

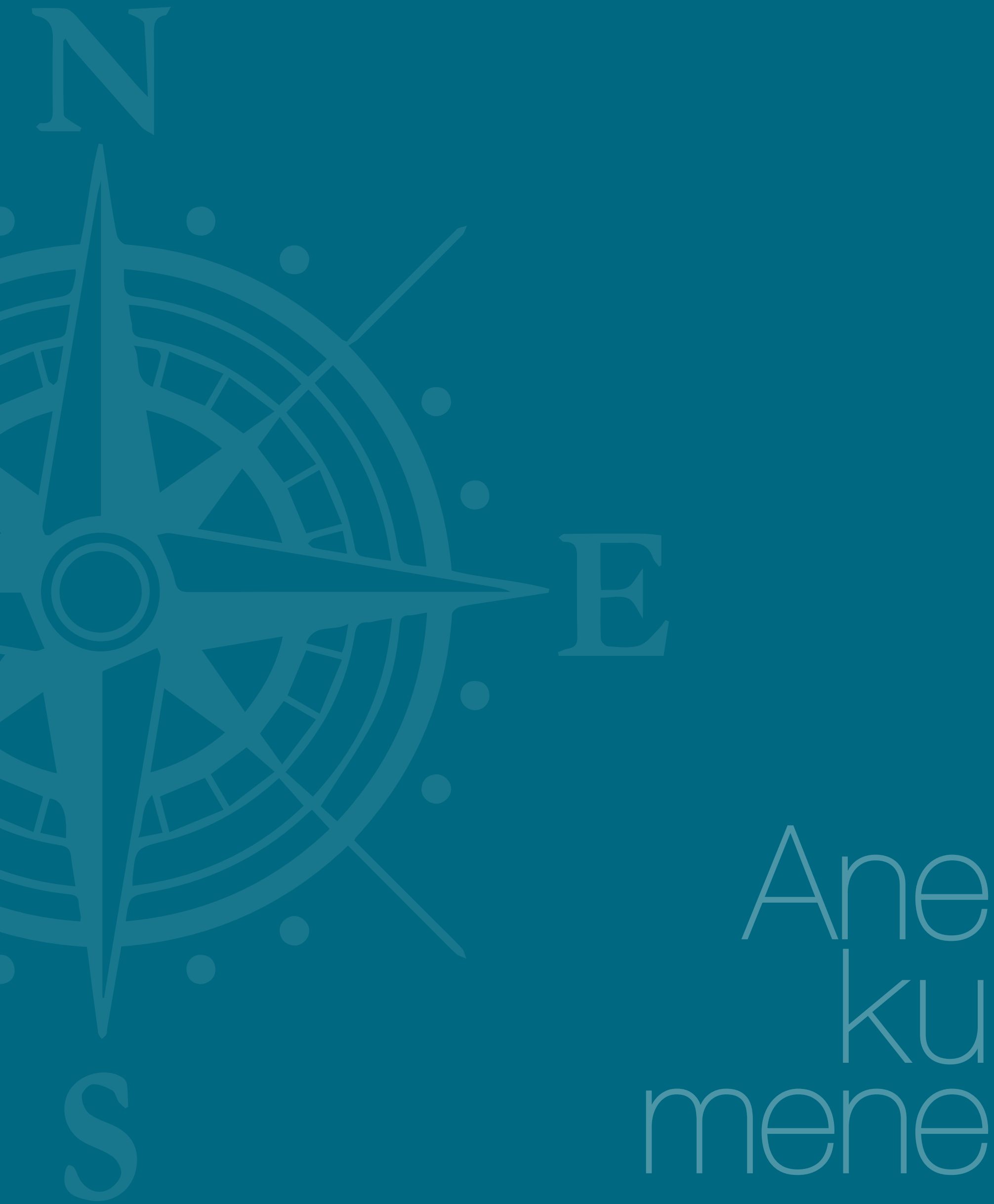


\title{
La construcción social del espacio: Una lectura desde la narrativa y la Geografía
}

\section{A construção social do espaço: Uma leitura desde a narrativa e a Geografía \\ The Social Construction of Space: A Reading from Narrative and Geography}

\author{
Efraín Eduardo Núñez Arévalo ${ }^{1}$
}

\section{Resumen}

Aproximarse a la interpretación de la construcción social del espacio visibilizando concepciones y representaciones que se hacen de este-mediante la lectura de elementos simbólicos presentes tanto en novelas que hablan de una zona como en las experiencias cotidianas de sus habitantes- facilita la construcción y el fortalecimiento de la identidad de un pueblo, en este caso en particular del municipio de La Mesa- en el departamento de Cundinamarca, Colombia. El ejercicio investigativo se convierte en un recorrido vivencial y simbólico que permite conocer paisajes naturales y culturales del municipio, sus recursos y su relación con las actividades económicas, la cultura y las tradiciones, así como el proceso de transformación del espacio y sus implicaciones políticas, sociales y ambientales.

\section{Palabras clave}

Espacio geográfico;

representación;

concepción; novela

1 Institución Educativa Liceo Campestre La Mesa. Maestría en Estudios Sociales, línea de investigación Construcción Social del Espacio- Grupo de investigación Geopaideia- upN. 


\section{Palavras chave}

espaço geográfico; representação; conceitos; novel

\section{Keywords}

geographic space; representation; concepts; novel

\section{Resumo}

Realizar uma abordagem para a interpretação da construção social dos conceitos de espaço e produção de representações visíveis que são feitas do mesmo; através da leitura de elementos simbólicos que podem ser encontrados em ambos os romances que falam de uma área, como nas experiências diárias das pessoas que vivem, podem permitir a construção e fortalecimento da identidade de um povo como é o caso particularmente no município de La Mesa Cundinamarca Colômbia. O exercício de pesquisa torna-se uma jornada experiencial e simbólico que permite conhecer paisagens naturais e culturais do município, seus recursos e sua relação com as atividades econômica, cultura e tradições, bem como a transformação do espaço e suas implicações políticas, social e ambiental.

\section{Abstract}

Approaching the interpretation of the social construction of space and highlighting its representations-through the reading of symbolic elements that can be found both in novels about an area and in their inhabitants' daily experiences-may enable the construction and strengthening of a town's identity, as in the particular case of the municipality of La Mesa in Cundinamarca, Colombia. The research becomes an experiential, symbolic journey that allows knowing natural and cultural landscapes of the municipality, its resources and their relation to economic activities, culture and traditions as well as the transformation of space and its political, social and environmental implications. 


\section{Introducción}

El presente artículo presenta los resultados del proceso investigativo que se adelantó en el marco de la Maestría en Estudios Sociales, en la línea de investigación Construcción Social del Espacio. Se propone dar cuenta de las implicaciones que tiene hablar de la construcción del espacio geográfico, visibilizando representaciones y concepciones que se hacen del mismo, por medio de la lectura de elementos simbólicos y signos que se pueden encontrar tanto en la literatura como en las experiencias cotidianas verbalizadas de jóvenes.

Para el desarrollo del tema se han considerado las transformaciones en las relaciones económicas, políticas, sociales y culturales dadas en los contextos globales contemporáneos, que hacen necesario pensar los problemas de conocimiento de la realidad socio-histórica, no desde el ángulo de una sola disciplina sino desde perspectivas transdisciplinares para el análisis de nuevos o renovados objetos de estudio, como el concepto de espacio geográfico en cuanto categoría y objeto de análisis de la geografía. Esto permite que se amplíen los intereses investigativos de esta ciencia hacia campos emergentes que sacan provecho de la historia, la globalización, los estudios de género, la violencia, la religión, y en lo que concierne al proceso de investigación, a la subjetividad y la literatura, en relación con el espacio como construcción social.

Luego de hacer una balance al estado de la cuestión de la discusión sobre la que versa la investigación, cabe destacar que los estudios geográficos relacionados o abordados desde la literatura, o estudios geo-literarios, como propone Lévy (en Lindón \& Hiernaux, 2006), han empezado a consolidarse y construirse. No obstante, hay que reconocer que tales estudios apenas están iniciando y en general se concentran en propuestas en las cuales se reflexiona sobre la importancia de emplear la literatura como forma didáctica de la enseñanza del espacio o como herramienta e insumo en la investigación geográfica. Dentro de las propuestas más significativas que aportan directamente al proceso se encuentra La literatura: una estrategia para la enseñanza y comprensión de la geografía en la escuela, de los profesores Alexánder Cely Rodríguez y Nubia Moreno Lache (2006), obra en la cual

... se interrelacionan diferentes factores que intervienen en el proceso de enseñanza y aprendizaje de la geografía, en particular desde la relación que se establece a partir de la literatura como estrategia de enseñanza de la geografía y específicamente de la geografía urbana, posibilitando el desarrollo de aprendizajes urbanos para desarrollar competencias espaciales en la relación ciudad-individuo. En ese mismo orden de ideas se interrelacionan diferentes elementos que permiten introducir de manera específica el concepto de ciudad y la importancia de ser estudiada, interpretada, leída y releída para poder construir y re-construir nuevas formas de interactuar con y en ella (Cely \& Moreno, 2006, pp. 248-260).
Para los autores, la literatura presenta fundamentos válidos que permiten comprender y determinar la incidencia de factores sociales, culturales y afectivos que corresponden a la regulación del individuo dentro de un núcleo social, modificar la concepción de espacio y evidenciar las percepciones espaciales como reflejo de la cultura en la cual se desarrollan los estudiantes. Además, destacan la literatura como un tipo especial de saber, que es pertinente como estrategia en la enseñanza y aprendizaje de la geografía pues, a través de la literatura se obtiene información y conocimiento sobre un espacio geográfico determinado en un tiempo determinado.

Así mismo, los autores en el artículo "Geografía y literatura, una alternativa para la enseñanza y comprensión del espacio geográfico" (Cely \& Moreno, 2008, pp. 57-97), reflexionan sobre el concepto de espacio geográfico referido a la ciudad y su enseñanza y aprendizaje; además deliberan sobre el uso de la literatura como estrategia de aprendizaje. El artículo parte de los siguientes interrogantes

¿Qué relación se puede establecer entre geografía, ciudad y literatura? ¿Por qué es posible pensar el conocimiento de lo espacial a partir de la literatura? ¿Cómo se puede potenciar el uso de la literatura como estrategia didáctica en el proceso de enseñanza-aprendizaje de la geografía? (Cely \& Moreno, 2008, p. 58).

Uno de los mayores aportes que hace el artículo tiene que ver con la concepción e interpretación del espacio geográfico por medio de la literatura, pues mencionan que esta permite identificar diversos procesos de pensamiento espacial. Por ejemplo, con la literatura se puede hablar del proceso icónico cuando se expresa la construcción de imágenes y esquemas espaciales, en donde lo simultáneo y lo figurativo equivalen a una representación imaginativa. También mencionan que: "a través de la literatura se puede hablar del proceso simbólico que se presenta cuando se hace referencia y se categorizan las características del espacio geográfico" (Cely \& Moreno, 2008, p. 64).

Otra propuesta que cobra validez en esta perspectiva es la desarrollada por la profesora Martha Llorente (2012) en la Cátedra de Literatura y Espacio Habitado, publicada como artículo en la revista Diagonal, número 31. Allí se analiza cuál es el significado del espacio habitado, contemplado en el espejo de la literatura. En este sentido se cuestiona: ¿Qué parte de la experiencia de habitar han recogido la literatura, la palabra pronunciada y el texto? Así, se propone entender las razones que legitiman este recurso para comprender la experiencia del espacio, definiendo el juego de las relaciones mutuas entre el espacio vivido y la palabra depositada.

La propuesta acude a los estudios de literatura comparada, para dar cuenta de la afluencia diferenciada y las capacidades expresivas que cruzan puentes entre distintas realidades sociales y culturales. En esta medida la literatura se entiende como un conjunto de tradiciones diversas que promete ayudar a descifrar el sentido de este elemento funda- 
mental de la cultura que es el espacio habitado. Con esta perspectiva se trata de mostrar y defender el poder multiplicador y expresivo de la literatura frente al espacio y a la dificultad de conocerlo solo a través de los análisis de la propia realidad material.

En el terreno específico de la literatura, se presenta una cuarta propuesta, titulada El espacio en la literatura: distinciones elementales y evidencias introductorias, de Janusz Slawinski (1989), historiador y crítico literario. El autor deja entrever que la problemática del espacio ha sido relegada a un segundo plano, priorizando en literatura otro tipo de problemáticas, como la del narradory la situación narrativa, la problemática del tiempo, la problemática de la morfología de la fábula; o, últimamente, la problemática del diálogo y la dialogicidad en la obra de arte.

En la propuesta, el objetivo del autor no es declararse a favor de un purismo metodológico, pues él considera que todos los tipos de reflexiones son admisibles en idéntica medida y se pueden combinar de diferentes maneras; sin embargo, desarrolla en profundidad, desde la perspectiva metodológica de la espaciología literaria, el espacio como componente de la morfología de la obra, pues las demás son el sustrato de todas las cualidades, los significados y los valores que son atributos de los fenómenos espaciales.

Finalmente, desde esta perspectiva, el espacio se constituye en un objeto de análisis en la medida en que fue hecho, creado en la obra, y funciona en ella. Señala además que la constitución del espacio presentado transcurre en tres planos de unidades morfológicas de la obra, que son: el plano de la descripción, el plano del escenario y el plano de los sentidos añadidos. Como vemos, la propuesta permite evidenciar que la búsqueda sobre el espacio, en general, puede presentarse en el enunciado literario de la misma manera como se presenta en él las búsquedas sobre el tiempo, la personalidad o las relaciones sociales.

\section{Práctica y sentido de la geografía: senderos y posibilidades}

En las tres últimas décadas, la geografía ha experimentado transformaciones significativas, que cobran mayor profundidad en el contexto de crisis de las paradigmas más consolidados de las ciencias sociales y, en particular, a la luz del denominado giro cultural, que planteó el redescubrimiento de la dimensión cultural en la geografía y su presencia, de una forma u otra, en casi todos los campos de la disciplina. En este contexto, el objeto mismo de la geografía, el espacio o la espacialidad de la vida social, parece transformarse y florecer en el conjunto del conocimiento y atraer diversas miradas procedentes de distintas disciplinas. Para el geógrafo contemporáneo Edward Soja, el cambio va significar lo que él ha llamado el giro espacial:
Durante mucho tiempo muchos estudiosos, muchos geógrafos, han trabajado para poder destacar la importancia de la geografía y la importancia de la perspectiva espacial en los estudios sin tener una respuesta demasiado fuerte [...] en 1990 se produce una transformación en ese sentido y las diversas disciplinas comienzan a recoger a la geografía y a los estudios del espacio; comienzan a reconocerlos y a incorporarlos en sus trabajos transdiciplinarios [...] lo que conocemos como giro espacial, entendido como un cambio ontológico, una lucha ontológica, es decir, un cambio en la manera más bien básica de ver la existencia humana, de comprenderla (Soja, 1997, p. 72).

Autores contemporáneos no dudan en señalar que el espacio geográfico debe leerse como el espacio construido, lugar en el cual se desarrolla la acción humana, el territorio que se ordena y gobierna, donde se manifiestan los intereses políticos y se ejerce poder, desde donde se puede interpretar el pasado y soñar la construcción de un futuro, aquel que es habitado por diversidad de grupos étnicos con dificultades y problemas sociales.

En este sentido, no se perpetúan los campos tradicionales de aquella geografía anónima, naturalizante y sin sujeto (Gurevich, 2005), ya que estos casi siempre dan cuenta de esos ámbitos o recortes de la realidad geográfica más o menos nítidos, o al menos posibles de señalar. No obstante, tampoco se invisibilizan. Se trata de abordarlos desde un concepto complejo de "campos emergentes de la geografía" (Lindón y Hiernaux, 2006), que aparte de ámbitos como la ciudad, el barrio, las calles, los mercados, las industrias y el comercio, incorporan otros aspectos, como las formas de estudiarlos, desde qué tipo de mirada y las nuevas escalas espaciales desde donde abordar el estudio. En fin, un sinnúmero de posibilidades que re-significan la práctica y el sentido de la geografía, y su importancia en el entendimiento del mundo y la realidad social desde los actores.

La propuesta de involucrar en la investigación diferentes enfoques geográficos para dar cuenta del tratamiento de la categoría de espacio geográfico como una producción, como una construcción social, significa el derecho a reconstruir las relaciones espaciales, de modo que el espacio deje de ser una estructura absoluta y fija de la acción para transformarse en una condición más amable, relativa y relacional de la vida social: "Debemos romper la espacialización impuesta por la mente con el objeto de recuperar el contacto con el núcleo de lo que verdaderamente está vivo, lo que subsiste en la dimensión temporal" (Massey, 2005, p. 112). Implica construir el espacio, más que reivindicar el derecho a circular dentro de un mundo pre-ordenado espacialmente en el que los intereses de las clases hegemónicas han definido a su antojo las prácticas espaciales, las representaciones del espacio y los espacios de representación. La geografía forma parte de la teoría social, y le corresponde desarrollar y reafirmar el carácter espacial de la vida social reivindicado por las tendencias posmodernas. 
Al respecto es necesario hacer un acercamiento a enfoques como la geografía humanística, para que se hagan cargo de la heterogeneidad fruto de las subjetividades, de la variedad y la diversidad. Es necesario acercarse libre de perjuicios a la mente del ser humano, comprender au conducta espacial o geográfica y entender siempre que las personas no se mueven en un espacio abstracto, sino en uno concreto y personal, lo que a su vez permita el estudio de aspectos determinados de la dimensión subjetiva de la realidad, en cualquiera de sus formas, a partir de una continua reflexión sobre fenómenos que no tienen un reflejo estrictamente material, aunque sí profundas repercusiones en la vida cotidiana de las personas.

En vez de tener como objetivo la búsqueda de leyes generales, ahora se pretende una comprensión de los hechos que se logra a través de un contacto de los mismos desde adentro, es decir que el geógrafo participa y se compromete con lo que estudia (González, 2003, p. 995).

Desde esta perspectiva se muestra que: "el espacio está lleno de significaciones y valoraciones e incluso se llega a afirmar que las personas demuestran sentido del lugar, cuando aplican a él su discernimiento estético y moral" (Bertrand, 1987, p. 6). Y para dar cuenta de este intrincado proceso de conceptualización y teorización del espacio geográfico se acude a la representación, dentro del marco de los estudios culturales como proceso por el cual los habitantes de un lugar usan el lenguaje para producir sentido. Esta disertación teórica que involucra el proceso de elaboración de representaciones tiene la importante premisa de que los objetos, personas, eventos del mundo como la construcción del espacio no tienen por sí mismos ningún sentido fijo, final o verdadero. Somos nosotros, dentro de las culturas, los que hacemos que las cosas signifiquen.

Sin descuidar que las representaciones, según el profesor Wilmer Villa (2008), se producen siempre dentro de los límites culturales y las fronteras teóricas que, por tanto, están implicadas necesariamente en economías particulares de verdad, valor y poder; por ello, es preciso situar las representaciones en un campo complejo de economías racionales y afectivas que examinen cómo los individuos elaboran significados y realizan implicaciones emocionales en dichas construcciones, lo que nos permite evidenciar la complejidad del proceso constitutivo de la realidad social frente al propósito de la investigación al resaltar las representaciones y concepciones como elementos que expresan el significado y sentido del espacio geográfico.

En consecuencia, la novela se presenta como la representación del mundo actual, como un intento por plasmar a través del lenguaje escrito la totalidad del mundo que vivimos, con frecuencia de un sector exactamente delimitado, pero como el resultado del profundísimo deseo de abarcar el mundo como espacio y este a su vez como elemento estructurante del mundo, que se limita a ser en realidad el espacio en que viven individuos y del que se hacen experiencias personales; en el mejor de los casos, el espacio entendido como portador y tal vez generador de grandes acontecimientos,

Este género literario favorece la revelación del mundo partiendo del espacio como sustrato, como sustancia de la misma. Por ello, comprender, a través de productos artísticos como la novela, el mundo como ambigüedad, es tener que afrontar no una única verdad que se contradice, sino poseer como única certeza la sabiduría de lo incierto.

En suma, la literatura, y en especial dentro de ella la novela, aparece como algo más que arte: "es poesía, lenguaje y creación de mundo; expresa artísticamente la polifonía de lo social” (Cárdenas, 1999, p. 44). Por ello la geografía, en ese intento por renovar su quehacer científico, debe propender por implementar el uso de una prosa evocadora y una lírica emotiva, al tratar de definir su objeto de estudio; y más aún con los campos emergentes de la geografía contemporánea, desde los cuales se tiene la oportunidad de responder con placer y admiración a la maravilla del escenario natural. La mayor precisión y el aparato científico no necesitan ni deben eliminar la sensibilidad, sino más bien intensificarla. Por tanto, defender el estudio del espacio geográfico a través de disciplinas como la literatura es entender que hay que abrir espacios de reflexión sin pretensiones de objetividad absoluta. Permitir que en la geografía se establezca el modo en que la literatura ilumina el espacio real que habitamos, que permita a la literatura expresar qué rincón del espacio geográfico dado al olvido de todos los tiempos es capaz de rescatar; que permita comparar la forma en que la literatura sabe hacer permanecer los hábitos y las experiencias relativas al hecho de habitar, más allá de la ruina de las estructuras materiales que han conformado el marco espacial de la vida, más allá de los espacios de la geografía que han dado paisaje y entorno a los lugares que habitamos.

En fin, de lo que se trata es aportar al debate de los estudios geo-literarios una continua reflexión del espacio geográfico que contemple la posibilidad de emplear novelas como textos literarios, que hablan del espacio geográfico, como elementos que visibilizan experiencias y subjetividades de los actores sociales que intervienen y habitan en el espacio, pasando por el análisis de las maneras como se producen y legitiman ciertas formas de estructuración de la realidad sociohistórica en los procesos de formación de los habitantes, para ver cómo a través de la vivencia y en la cotidianidad se utiliza el lenguaje y se difunden modos selectivos de conocimiento que inciden en la configuración de concepciones, representaciones y prácticas que se establecen sobre, en, desde y con el espacio. Por ello, en la investigación se plantea la pregunta: ¿Cómo conciben y representan su espacio geográfico a través de la vivencia y la literatura los jóvenes de noveno, décimo y undécimo grados del colegio Liceo Campestre, del municipio de La Mesa? Para dar respuesta a este interrogante, se plantea como objetivo general: Interpretar concepciones y representaciones del espacio geográfico del municipio de La Mesa 
presente en los jóvenes de noveno, décimo y undécimo grados de la institución educativa Liceo Campestre, de La Mesa, a partir de las vivencias y la literatura de la zona.

\section{El espacio geográfico en el mundo de la vida}

La investigación y la práctica geográfica han cambiado significativamente en la segunda mitad del siglo xx. Su evolución como disciplina científica y académica ha ido acompañada de una fuerte reflexión sobre sus bases teóricas y metodológicas, así como sobre la viabilidad de las técnicas e instrumentos que se emplean para su estudio. Para García Ballesteros (1998), la preocupación de la geografía por dotarse de un cuerpo metodológico y técnico le ha permitido investigar las motivaciones de los hechos socio-espaciales, los significados, valores e interpretaciones de los lugares y de la vida cotidiana, lo que ha llevado a introducir en la disciplina un amplio abanico de métodos y técnicas denominadas genéricamente cualitativas. Estos, en muchos casos, se enlazan con viejas tradiciones de diferentes disciplinas, aunque ahora se renuevan y conectan con otras bases teóricas, como la fenomenología, el existencialismo y la teoría crítica.

Procedimentalmente la metodología cualitativa que se asumió para el proyecto de investigación no comenzó con un conjunto de hipótesis que hubo que verificar sino, por el contrario, con un acercamiento al lugar objeto de estudio a partir del planteamiento de la problemática y de reflexiones sobre la misma, con la intención de permitir que la investigación diera cuenta de la realidad. Tras el contacto con la realidad y según esta fue indicando, se elaboraron las categorías de análisis que se contrastaron y sometieron a una interpretación detallada, sin excluir procedimientos cuantitativos, como lo aconsejaban los objetivos específicos de la investigación. Es decir, el análisis cualitativo empleado comenzó con un acercamiento directo y detallado a la cotidianidad y a la experiencia de los lugares de los estudiantes del Liceo Campestre de La Mesa, para tratar de descubrir la estructura, los significados y los contextos de los hechos que allí se produjeron. El descubrimiento, la descripción y los significados que se obtuvieron son el resultado de una investigación enfocada en el estudio de los fenómenos sociales en el propio entorno natural y social en el que ocurrían, dando primacía a los aspectos subjetivos sobre las características objetivas.

Para Vasilachis (2006), tres elementos comunes forman parte de la rica variedad de estrategias y técnicas que se pueden emplear. Así, se entiende que la investigación cualitativa desarrollada está:

fundamentada en una posición filosófica que es ampliamente interpretativa en el sentido de que se interesa en las formas en las que el mundo social es interpretado, comprendido, experimentado y producido, b) basada en métodos de generación de datos flexibles y sensibles al contexto social en el que se producen, y c) sostenida por métodos de análisis y explicación que abarcan la comprensión de la complejidad, el detalle y el contexto (p. 25).

Lo que se encontró es que esta manera de investigar se considera una forma de pensar más que una colección de estrategias; un acto interpretativo que explica, define, clarifica, elucida, ilumina, expone, parafrasea, descifra, traduce, construye, aclara, descubre, resume. El método cualitativo empleado constituye un modo particular de acercamiento a la indagación: "una forma de ver y una manera de conceptualizar, una cosmovisión unida a una particular perspectiva teórica para comunicar e interpretar la realidad" (Morse, 2005, p. 287). Por ello, se acudió a la investigación cualitativa, pues el propósito era interpretar, volver al caso individual significativo en el contexto de la teoría, proveer nuevas perspectivas sobre lo que conocemos y decir más de lo que las personas piensan, decir qué significa e implica ese pensamiento.

Una vez definida la investigación cualitativa como tipo de investigación en la que se sustentó el proyecto, es de resaltar que esta misma orientó, dentro de sus enfoques o escuelas, la metodología asumida para la interpretación. Lo que en definitiva llevó a plantear una semiosis-hermenéutica como forma de producción de conocimiento y además como plan establecido para la consecución del objetivo propuesto.

La hermenéutica y semiótica textual no son dos disciplinas rivales que se enfrenten en el mismo nivel metodológico. La semiótica solo es una ciencia del texto, que: "trata legítimamente de someterse a una axiomática precisa que la inscribe en una teoría general de los sistemas de signos" (Vásquez, 2008, p. 77). La hermenéutica es una disciplina filosófica, que surge al preguntarse ¿Qué es comprender, qué es interpretar?, en relación con la explicación científica. La hermenéutica invade la semiótica, en la medida en que implica, como su segmento crítico, una reflexión sobre los supuestos que se consideran obvios en la metodología de las ciencias sociales en general y en la semiótica en particular.

Según lo propuesto por Gadamer (1992), la hermenéutica aparece como una teoría interpretativa que posibilita entender la realidad construida a través de discursos y actos dotados de significado. Así, la interpretación no se reduce a los textos y a la comprensión histórica que se puede alcanzar por medio de su análisis, sino que:

Todas las estructuras de sentido concebidas como textos [...] hasta las motivaciones conscientes o inconscientes de la acción humana son susceptibles de interpretación. Esta pretende mostrar, no ya lo que es obvio y aparente sino las verdaderas y latentes concreciones de sentido de la acción humana, aunque lo haga [...] mostrando cómo nos pasan inadvertidas las condiciones sociales e históricas de nuestro pensamiento [...] Ningún marco interpretativo es arbitrario ni, menos aún, "objetivo2 [...] la reflexión hermenéutica demuestra que hay en él unos presupuestos ocultos que son decisivos (Gadamer, 1992, p. 372). 
Desde la semiosis, Verón (1998) advierte que toda producción de sentidos es necesariamente social y que todo fenómeno social, en una de sus dimensiones constitutivas, es un proceso de construcción de sentido. Lo que señala el autor a través de esta relación es que el sentido aparece en lo social y lo social depende del sentido; en suma, la producción de sentido es tanto dialógica como discursiva, por tanto “... sólo en el nivel de la discursividad el sentido manifiesta sus determinaciones sociales y los fenómenos sociales develan su dimensión significante" (Veron, 1987, p. 126).

En consecuencia, con la hermenéutica la investigación buscó interpretar y dar significado al mundo de la vida y a la acción humana, que encauzada en un enfoque fenomenológico permitió acercarse aún más al análisis y la explicación del sentido de las acciones, de la realidad que se convierte en objeto de conocimiento para la investigación. Por su parte, con la semiótica se reflexionó y reconoció que el lenguaje configura y estructura la experiencia vivida, y se convierte en el medio fundamental para la comprensión de la realidad. Bruner (1997) menciona que es a partir del lenguaje que el sujeto reconstruye la realidad social y su mundo posible.

Así, la semiosis-hermenéutica como propuesta metodológica de la investigación se aproximó a la hermenéutica profunda de Paul Ricoeury John Thompson, pues partió del análisis de la vida cotidiana y supuso posteriormente tres procedimientos principales que se aplicaron al análisis del corpus del proyecto, en torno al espacio geográfico como objeto de estudio: 1) análisis socio-histórico, 2) análisis formal o discursivo, y 3) la interpretación/reinterpretación como síntesis de ambos, que capta lo que las formas simbólicas y los signos representan, a partir de la creación de un nuevo significado posible.

Figura 1 Esquema analítico

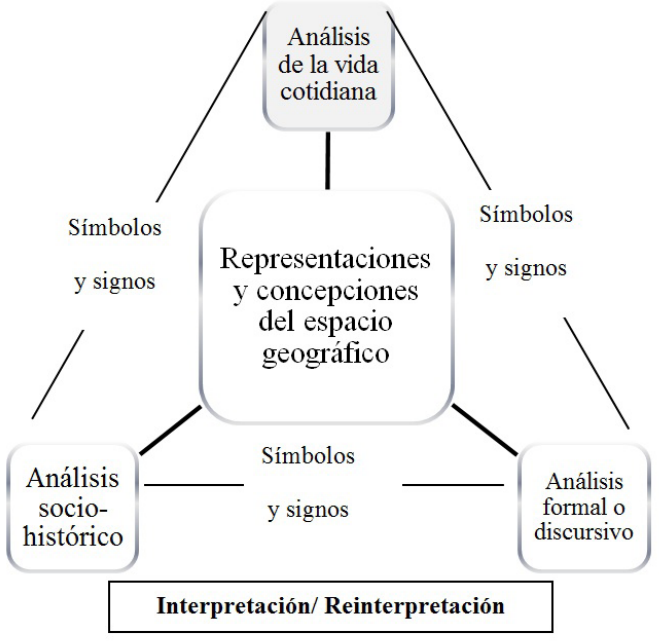

Fuente: Elaboración propia, 2014
Es necesario aclarar que la selección de las técnicas y los instrumentos de recolección de la información dependieron principalmente de la problemática que se desarrolló; por lo tanto se ajustaron a ella. Así, las técnicas y los instrumentos son el resultado de un proceso que buscó la contrastación y comprobación de todos los elementos que componen la investigación: los enfoques teórico, práctico, metodológico y epistemológico, que giran en torno al espacio geográfico como objeto de conocimiento.

La investigación no se ciñó a una técnica, sino que en ella se relacionaron diferentes técnicas e instrumentos que formaron parte del proceso en fases y respondieron a los objetivos específicos planteados para alcanzar el objetivo general de la investigación. Al plantear de esta manera la ruta metodológica, se trató de buscar consistencia en la información de los distintos niveles para llegar a una interpretación/reinterpretación de las concepciones y representaciones de los estudiantes sobre espacio geográfico como construcción social. De ahí que instrumentos de investigación como los mapas mentales, el análisis literario a través del software de análisis y procesamiento de datos cualitativos Atlas ti, y la salida de campo empiecen a verse como una manera de reconocer lo subjetivo, en la medida en que permiten dar cuenta de la cotidianidad y de la experiencia personal del espacio.

\section{Sentido y significado de los hallazgos: interpretación de La Mesa a través de la vivencia y la narrativa}

El estudio se desarrolló en tres fases. La primera buscó la identificación de las concepciones y representaciones del espacio geográfico a través del instrumento mapa mental previo, a manera de diagnóstico, y de la herramienta informática Atlas ti, que permitió codificar las obras literarias (novelas seleccionadas). En la segunda, a manera de proceso de aprendizaje adelantado por los estudiantes, se empleó la salida de campo como instrumento que permitió potenciar la observación consciente y la recolección de información de fuentes primarias y secundarias sobre La Mesa como espacio geográfico. En la tercera, se obtuvo la interpretación/ re-interpretación y el planteamiento de conjeturas sobre La Mesa como espacio geográfico, por medio del instrumento mapa mental posteriory de los escritos que complementan los mapas mentales elaborados por los estudiantes, productos de la salida de campo y de la lectura de las obras. Tanto la salida de campo como la lectura de las novelas se convirtieron en instancias que ampliaron el panorama de reflexión de La Mesa por parte de los estudiantes. Ello se reflejó en las concepciones y representaciones posteriores a estas dos actividades, por lo cual se infiere que enriquecieron la comprensión e interpretación del espacio geográfico.

Los datos que se obtuvieron de los instrumentos de investigación fueron clasificados y organizados de acuerdo con dos variables fundamentales que responden a: 
I. La estructuración espacial del municipio de La Mesa. Dentro de ella se interpretó la continuidad (integración entre los elementos que conforman el mapa mental), la localización relativa (correspondencia tanto en el dibujo como en la realidad de la orientación que tienen los objetos), y la vecindad (coherencia en la proximidad tanto en el dibujo como en el mundo real de los objetos representados).

II. La complejidad de las concepciones y representaciones espaciales que se encontraron tanto en los mapas mentales como en los relatos que hicieron los estudiantes; y a la par, las concepciones y representaciones que se encontraron en las obras literarias seleccionadas. Específicamente dentro de esta variable se revisaron e interpretaron tanto las novelas como los dibujos; se identificaron y caracterizaron dones naturales, tales como árboles, animales, ríos, montañas, el sol, entre otros; objetos artificiales del espacio, como casas, edificios, calles, puentes, carros, etc.
Además se analizó si en las representaciones se habló o se dibujaron personas y, por último, si se hizo referencia a objetos imaginarios, todo ello con el fin de interpretar cómo se construye socialmente el espacio. Este análisis se vinculó a una interpretación semiótica en la que se resaltaron posibles significados de los elementos que componen el espacio geográfico representado.

Los datos que se recolectaron son sensibles y flexibles así como los mismos instrumentos, esto debido a que cuando se aplicaron los instrumentos con la población sujeto de estudio se evidenció, por ejemplo con el mapa mental previo, que eran instrumentos insuficientes al momento de representar a La Mesa teniendo como marco de referencia, por parte de los estudiantes, su propia vivencia y experiencia como habitantes de este espacio geográfico. Por tanto, se hizo necesario complementar las instrucciones de elaboración con pequeños relatos que evidenciaron lo que para ellos significa el municipio de La Mesa. La siguiente representación y concepción que se obtuvo mediante la aplicación de estos instrumentos se presenta en el mapa mental 1.

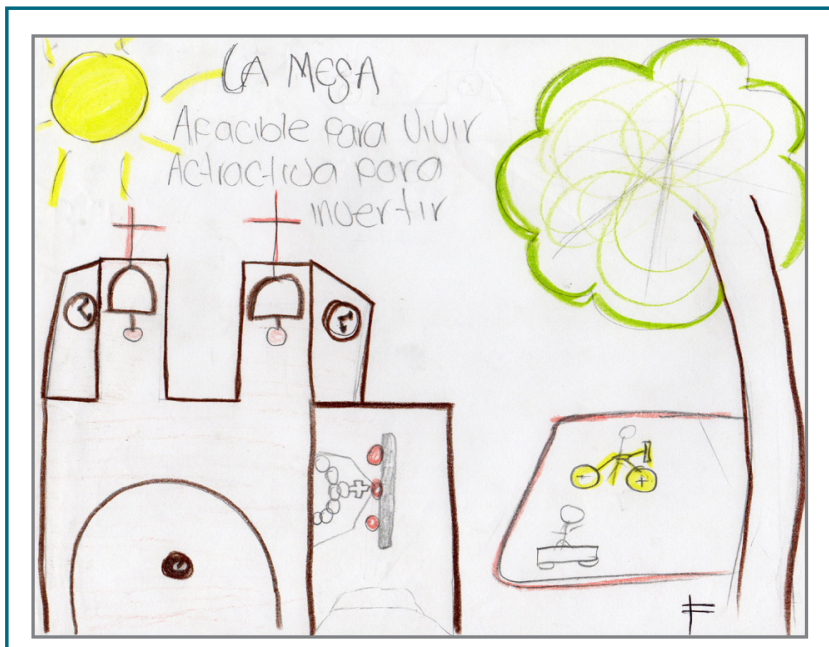

Es un pueblo moy diferente a anzable y cordial aueces la gente es muy udifaente al momento de ayudar a las demas, tamblea doode la geilte urve de 101 que extar es exe lugar dende las personas versionadas es decir las uejitos que estair carrados de uruir en cina cludad, deciden uivir aca Eserie a consprar y uender

Es un pueblo muy diferente a amable y cordial a veces la gente es muy indiferente al momento de ayudar a los demás, también donde la gente vive de los chismes, es ese lugar donde las personas pensionadas es decir los viejitos que están cansados de vivir en una ciudad, deciden vivir acá. Es un lugar donde hay mucho comercio, donde la gente del campo viene a comprar y vender.

Mapa mental 1. La Mesa: apacible para vivir, atractiva para invertir Fuente: Estudiante del grado 11

En esta representación icónica de La Mesa la estudiante, además de dibujar elementos distintivos (la iglesia, la ceiba y la plazoleta) del parque central del municipio, permitió referenciar el carácter históricamente constituido de ese lugar antropológico al que se denomina pueblo, del que se han construido muchos imaginarios. Una expresión fuerte de la estudiante que no se puede obviar es: "la gente vive de los chismes", expresión relacionada con el refranero popular, que sentencia: "pueblo chico, infierno grande", como una manera de sugerir y resumir al tiempo las angustias y desesperanzas de los habitantes, pero también como una forma de recordar el control social que se instituye en este ambiente, como lo evidenció otro estudiante (véase el mapa mental 2). 


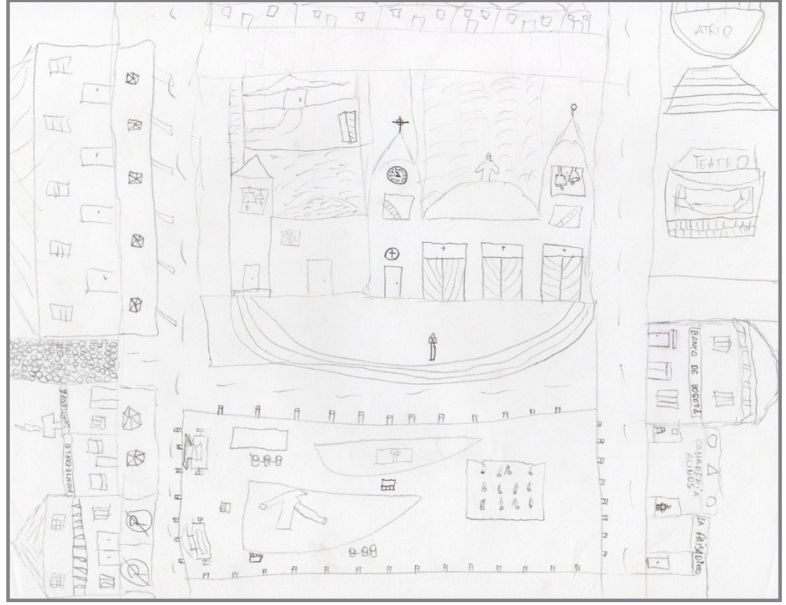

La Mesa Cundinamarca es un pueblo turístico de Colombia, es un pueblo pequeño en el cual los acontecimientos se difunden muy rápido. Como su población vive en la cotidianidad cualquier hecho que pase es de extremo interés.

Mapa mental 2. La Mesa y su cotidianidad

Fuente: Estudiante del grado 10
En los dos ejercicios anteriores fue importante señalar la referencia al pueblo como un lugar pequeño, en el que la iglesia se destaca como elemento central de todo pueblo. Es de anotar que no solo en estas dos representaciones la edificación más importante y la que más resalta del municipio es la iglesia; ocurrió lo mismo en 26 de las 29 representaciones que hicieron los estudiantes. Este hecho no es arbitrario. Fue necesario involucrar el carácter histórico de la construcción social del espacio, ya que los pueblos de Colombia se constituyeron sobre la base del orden colonial, están erigidos siguiendo el esquema del damero, donde en el marco de la plaza se situaron los poderes eclesiásticos, civiles, militares y las casas de los más acaudalados.

Los mapas mentales elaborados por los estudiantes, además de haber sido enfáticos en señalar el parque principal como representación del municipio de La Mesa, evidenciaron factores recurrentes de identificación de lo que se conoce como espacio geográfico; lo que Milton Santos (2000) definió como un "conjunto indisoluble, solidario y también contradictorio de sistemas de objetos y de acciones" (Santos, 2000, p. 84). En este sentido fue conveniente señalar los objetos artificiales, dones naturales y objetos imaginarios dibujados en los mapas mentales, de una manera más formal y descriptiva recurriendo a la tabla de códigos -documentos primarios que sintetizan los resultados de la sistematización y codificación de los mapas mentales (véase la tabla 1).

\begin{tabular}{|c|c|c|}
\hline \multirow{4}{*}{ Informe Atlas ti } & \multicolumn{2}{|c|}{ CODES-PRIMARY-DOCUMENTS-TABLE } \\
\hline & \multicolumn{2}{|c|}{$\begin{array}{c}\text { UH: [C: \Users\user\Dropbox\unidad } \\
\text { hermeneutica\resultados estructura del } \\
\text { espacio.hpr] }\end{array}$} \\
\hline & \multicolumn{2}{|c|}{ Código-filtro: Todos [29] } \\
\hline & \multicolumn{2}{|c|}{ Cita-filtro: Todos [100] } \\
\hline \multicolumn{2}{|c|}{ Elementos estructurales del espacio } & $\begin{array}{l}\text { No Elementos } \\
\text { representados }\end{array}$ \\
\hline \multirow{6}{*}{ Dones naturales } & perro & 1 \\
\hline & aves & 9 \\
\hline & árbol & 16 \\
\hline & nube & 2 \\
\hline & sol & 6 \\
\hline & nevados & 4 \\
\hline \multirow{11}{*}{ Objetos artificiales } & parque principal & 14 \\
\hline & iglesia & 17 \\
\hline & calle & 14 \\
\hline & casa & 10 \\
\hline & concha acústica & 3 \\
\hline & teatro & 2 \\
\hline & faro & 2 \\
\hline & fuente & 7 \\
\hline & mirador & 4 \\
\hline & moto & 6 \\
\hline & carro & 10 \\
\hline \multirow{3}{*}{ Personas } & nif̂o & 6 \\
\hline & hombre & 11 \\
\hline & mujer & 4 \\
\hline \multirow{4}{*}{ Objetos imaginarios } & cruz & 15 \\
\hline & reloj & 4 \\
\hline & campana & 8 \\
\hline & Jesucristo & 2 \\
\hline \multicolumn{2}{|c|}{ TOTALES: } & 177 \\
\hline
\end{tabular}

Tabla 1. Elementos estructurales del espacio, mapas mentales previos

Fuente: Mapas mentales elaborados por los estudiantes de los grados $9^{\circ}, 10^{\circ}$ y $11^{\circ}$. 
En el cuadro se evidencia el grado de complejidad del espacio geográfico, representado en el parque principal, pues tomando como referencia cada una de las representaciones que realizaron los estudiantes, se muestra que es el espacio que más elementos contiene. Allí están la iglesia, la fuente, los árboles de ceiba, los carros, las motos, las casas, las aves, el perro, las personas y desde allí se pueden apreciar los nevados, los miradores, el teatro, la concha acústica, las nubes y el sol. Por esta razón, para cada representación se registró y sistematizó el tipo de objetos artificiales, el tipo de dones naturales, el tipo de personas y de objetos imaginarios dibujados, como se muestra en la red semántica 1.

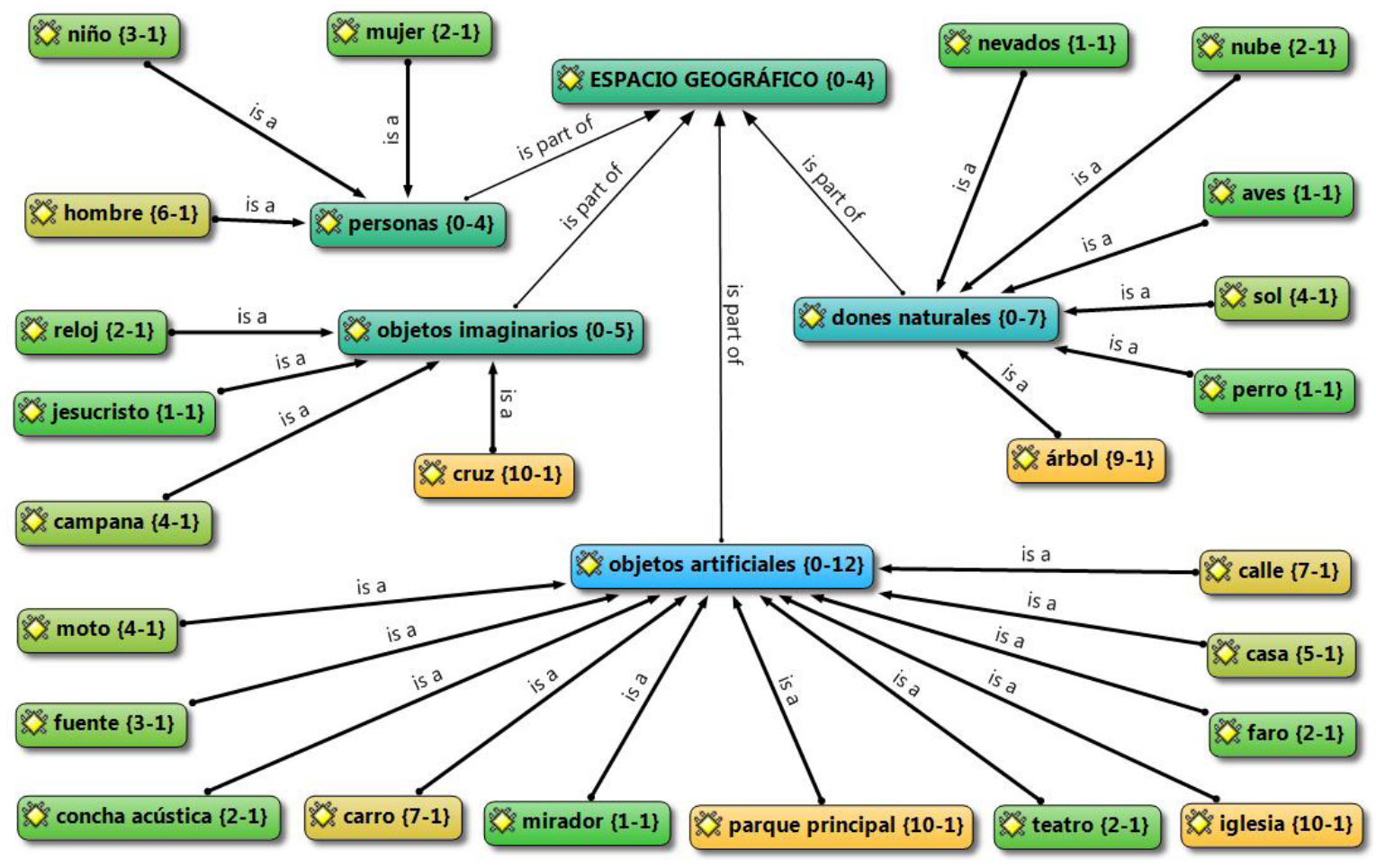

Red semántica 1. Sistemas estructurales del espacio

Fuente: Mapas mentales elaborados por los estudiantes de los grados $9 .^{\circ}, 10 .^{\circ}$ y $11 .^{\circ}$.

Esta interpretación y señalamiento de elementos fue fruto de percepciones cotidianas, las cuales tenían matices que debieron considerarse a la luz de la producción de representaciones espaciales, puesto que variaron de acuerdo con la existencia de múltiples concepciones sobre el espacio. Los elementos que más se destacaron fueron los clasificados como objetos artificiales. Esto sugiere que los estudiantes concibieron y representaron un espacio urbanizado e intervenido por el hombre, aunque no en todas las representaciones estuvo el mismo número de objetos; por ello se consideró que cada estudiante, de acuerdo con su acumulado cultural, estructuras de pensamiento, vivencias, entre otros, logró encadenar nuevos elementos percibidos, desde el entorno de su cotidianidad, para formar nuevas ideas, producto de las concepciones del municipio.
Algo similar fue lo que se interpretó y presentó con las novelas Los trabajadores de tierra caliente del escritor Medardo Rivas y la novela Angosta del escritor Héctor Abad Faciolince, puesto que en cada una de las historias narradas se involucró el espacio como elemento sustantivo, constitutivo y encadenador de la trama argumental. El espacio en las novelas se presentó como el fruto y resultado de la propia experiencia cotidiana de los escritores, secuela de habitar en uno de los tantos pueblos que conforman el territorio nacional; así mismo, el espacio construido respondió al contacto directo o indirecto de los personajes y a las acciones que realizan en cada historia, pues en él tuvieron lugar.

Estas características puestas en la novela matizaron la concepción y representación de La Mesa y de Angosta como espacios geográficos, más allá de ser solamente parte de los marcos narrativos que contienen 
a los otros elementos de la historia. Las novelas al igual que los mapas mentales se convirtieron en manifestaciones cognitivas pero a la vez artísticas de representación del individuo en su espacialidad, en donde se expresó la construcción de imágenes y esquemas espaciales, donde lo simultáneo y lo figurativo fueron equivalentes a una representación imaginativa. La literatura y la geografía se mezclaron en esta investigación para dar cuenta del espacio geográfico en tanto mixtura de todos los sistemas que lo conforman.

\section{El espacio vivido de los jóvenes y las espacialidades de la literatura}

La pretensión de este trabajo de investigación es lograr introducir el espacio geográfico como un tema fundamental no solo dentro del saber geográfico sino dentro del debate literario, y más aun dentro del análisis y la crítica literaria que han relegado a un segundo plano esta sustancia que permite la existencia de una obra literaria. Además se pretende contribuir con el trabajo que se está consolidando y se ha comenzado a instaurar en la práctica geográfica considerando la literatura como herramienta y a su vez como insumo para hacer emerger la configuración social del espacio, sacando provecho del potencial no solo descriptivo que poseen textos como la novela, sino de esa pretensión literaria de recrear realidades a manera de totalidades que involucran lo social, espacial y temporal. La obra y el mundo representado en ella se incorporan al mundo real y lo enriquecen; $y$ el mundo real se incorpora a la obra y al mundo representado en ella, tanto durante el proceso de elaboración de la misma, como en el posterior proceso de su vida, en la elaboración de la obra a través de la percepción creativa de los oyentes lectores (Bajtín, 1990, p. 404).

El proceso de investigación permite sostener que cualquier pueblo de Colombia -o si se quiere, cualquier pueblo latinoamericano- como espacio no se agota en lo físico, sino que es una realidad compleja, inacabada, que se construye y reconstruye y que, en esa medida, su interpretación y su conceptualización, así como su realidad material, aún están en transformación. Una trasformación que no incluya a sus habitantes, en especial a sus jóvenes, no está pensada para el futuro, pues ellos son los que estarán encargados de decretar, modificar, estipular, imaginar la organización y construcción del espacio.

El espacio desde la perspectiva propia de la investigación permite considerarlo como el resultado de los procesos socioculturales que acontecen en él durante un momento dado. En un sentido ideal, el espacio geográfico se refiere a la convergencia de discursos y categorías mentales que atribuyen ciertas cualidades a las condiciones objetivas del mundo físico; mientras que en un sentido instrumental, el espacio se considera más como una condición circunstancialmente construida por los grupos humanos en relación con su uso, como un punto de referencia al que se adscriben para representar el mundo y a sí mismos.
Cada espacio geográfico aloja las experiencias, expresiones, símbolos y la significación de sus habitantes. El espacio debe ser el que pueda ser leído, significado, usado por los ciudadanos y todas aquellas personas que viven en él (habitantes que día a día ejercen como transformadores de su propia realidad espacial); debe ser la expresión de una amplitud de elementos prácticamente inconmensurables, dado que cada sujeto encuentra en su dinámica particular de vida, múltiples realidades y situaciones, que nutren su concepción de espacio, de práctica espacial. En este sentido, un municipio como La Mesa no solo es escenario; es actuación misma, la intersubjetividad se materializa allí. El pueblo expresa las construcciones de la subjetividad humana: la cultura, la sociedad, la política, la economía; es decir, cada aspecto que toca la condición del sujeto que ve cómo su pueblo se convierte en la ciudad contemporánea, la que se crea y se recrea desde la condición urbana del sujeto.

Cada individuo puede identificarse con la multiplicidad de matices que presenta su municipio, pueblo o ciudad y en esa medida se reconoce dentro de un mosaico de construcciones, de "pequeñas sociedades", de una condición de multietnicidad y pluriculturalismo vivos y palpables en la arquitectura, en las actividades cotidianas, en la forma como se organiza la vida del día a día en este espacio. Cada lugar como espacio vivido y cercano, como espacio mediatizado, además de leerse, en la actualidad se respira, se padece, se teme e incluso, se aborrece.

El espacio geográfico que motiva esta investigación es la materia prima de la que surgen las ideas y las imágenes que en la cotidianidad construyen sus habitantes y usuarios, porque precisamente la conjunción de sentimientos, emociones e ideas que pueden surgir del contacto diario con él, permiten que el sujeto lo perciba y lo construya en su pensamiento, para luego utilizarlo y vivirlo.

En definitiva, la geografía como ciencia social que estudia la relación del hombre con el espacio debe tener en cuenta todas aquellas circunstancias, actividades y procesos sociales, que crean y transforman el espacio. De ahí la importancia de entender que en la interpretación de cualquier fenómeno social, el espacio es también resultado de una proyección de la sociedad que lo conforma. Así, sociedad y espacio forman un todo indivisible en un sistema de interacciones, donde la sociedad se conforma a sí misma al tiempo que conforma el espacio.

El espacio geográfico, como afirma Milton Santos

... debe considerarse como un conjunto indisociable en el que participan, por un lado, cierta combinación de objetos geográficos, objetos naturales y objetos sociales, y por el otro, la vida que le colma y anima, es decir, la sociedad en movimiento. El contenido (la sociedad) no es independiente de la forma (los objetos geográficos), y cada forma encierra una fracción de contenido (Santos, 2000, p. 94). 
El espacio, por consiguiente, es un conjunto de formas, cada una de las cuales contiene fracciones de la sociedad en movimiento. Por ello no es desacertado decir que el espacio es el anclaje primordial en la realidad, dado que en él se da la corporeidad de lo cotidiano y la materialidad de la acción, bases de la heterogeneidad humana y de la reciprocidad.

En esta medida se hace necesario continuar implementando y desarrollando, dentro de la enseñanza de la geografía, enfoques comprensivos que permitan el conocimiento a través de la experiencia vital concreta, que otorguen un papel clave a la experiencia personal; en lugar de tener como objetivo la transmisión de conocimientos sobre leyes generales, se hace necesario continuar dando paso a enfoques que permitan una comprensión de los hechos a través de un contacto de los mismos desde dentro, prácticas y aprendizajes in situ.

Desde la perspectiva de la investigación se muestra que el espacio está lleno de significaciones y valoraciones e incluso se afirma que las personas demuestran sentido de lugar cuando aplican a él su discernimiento estético y moral, como se pudo ver en las obras y en los mapas mentales. Esta re-significación de la práctica geográfica significa acercarse libre de prejuicios a la mente del sujeto, para comprender su conducta espacial o geográfica, entendiendo siempre que estos no se mueven en un espacio abstracto, sino en uno concreto y personal.

La riqueza y complejidad de la geografía es tan amplia que la trayectoria que la ha precedido no imposibilita el que nuevos campos encuentren interpretaciones y alteridades para el estudio del espacio geográfico. Por ello, en la línea de investigación Construcción Social del Espacio se debe continuar ahondando y uniendo esfuerzos por el reconocimiento y la comprensión de dichos panoramas, así como por reconocer en la espacialidad una fuente valiosa de aprendizaje, indagación y formación de sujetos espacialmente conscientes de la complejidad de las sociedades y los territorios contemporáneos. Estos campos y panoramas de estudio se validan desde las mismas redes y comunidades académicas recientes. Puede ser que a partir del espacio geográfico se descubra el mundo, al mismo tiempo que se reafirme la identidad y la pertenencia de cada uno de nosotros.

En lo particular, como docente de Español y Literatura la investigación ha posibilitado entender que la lectura de una novela o de cualquier género literario, sin más motivo que el gusto o el entretenimiento, puede a su vez ser de provecho para tantos fines como la divulgación de conocimientos o en este caso un gran aporte al proceso de investigación para el estudio del espacio geográfico, para entenderlo en su conjunto, su surgimiento o el cómo se recreó en la narración, que en muchos casos es una extensión de la realidad.

Con la práctica investigativa se evidencia que el uso de los textos literarios además permite que los alumnos a través de su lectura identifiquen la relación que existe entre la sociedad y la naturaleza y la forma en que la humanidad construye y modifica permanentemente su espacio, y cómo lo perciben sus habitantes. Esto no ocurre en los libros de texto de geografía, por ejemplo, en donde existe la evidente división entre los conocimientos de Geografía Física y Geografía Humana.

El uso de textos literarios en geografía permite que los alumnos establezcan la relación entre los fenómenos físicos y/o naturales y los socioculturales, situación que con dificultad se realiza en espacio académico o existe en los libros de texto. Asimismo, se cumple uno de los objetivos de los retos que tiene la geografía en cuanto al manejo interdisciplinario de algunos temas y la relación entre los contenidos del plan de estudios con el propósito de propiciar un conocimiento integrador: un conocimiento complejo.

En general, los logros del uso de los textos literarios como apoyo para la investigación del espacio geográfico hasta el momento son satisfactorios, tanto por la disposición de los estudiantes para leer las obras seleccionadas y articularlas en sus producciones y del investigador, por los resultados de cada uno de los instrumentos aplicados. Además, esta ruta metodológica propició el desenvolvimiento de la imaginación y la creatividad de los alumnos cuando se solicitó que hicieran nuevamente el mapa mental, en el que dibujaron al municipio de La Mesa, así mismo en las producciones escritas que acompañaron los mapas.

Finalmente, debe considerarse que el hacer emerger la construcción social del espacio geográfico hace referencia al lugar desde el que se pueden construir múltiples enunciados, y la novela ha sido el medio para conservar parte de la historia de la humanidad y una forma de manifestar la ideología, las costumbres y la ética, además de incluir, en algunos casos, la descripción del medio que nos rodea. En consecuencia, son una manifestación que requiere, más allá de su lectura, un análisis integral de todos los factores que intervienen en su elaboración y en su contenido. 


\section{Referencias bibliográficas}

Abad, H. (2012). Angosta. Bogotá: Planeta.

Bajtin, M. M. (1990). Estética de la creación verbal. 4. ${ }^{a}$ ed. México: Siglo xxI.

Bertrand, C. (1987). La geografía humanista. El sentido de la naturaleza. Tesis doctoral. En: http://www.cristinabertrand.net/art/esp/img/ upload/TESIS-Geografia\%20Humanista.pdf.

Bruner, J. (1997). Realidad mental y mundos posibles: Los actos de la imaginación que dan sentido a la experiencia. Barcelona: Gedisa.

Cárdenas, A. (1999). Principios semioticodiscursivos para la lectura de la novela. Bogotá: Universidad Pedagógica Nacional.

Cely, A. \& Moreno, N. (2006, julio-diciembre). La literatura: una estrategia para la enseñanza y la comprensión de la geografía en la escuela. Geoenseñanza, 11(2). 249-260. ISSN 1316-60-77.

Cely, A. \& Moreno, N. (2008). Geografía y literatura, una alternativa para la enseñanza y comprensión del espacio geográfico. En: Cely, A\& Moreno N. Cotidianidad y enseñanza geográfica. Bogotá: Códice.

Gadamer, H. G. (1992). Verdad y método II. Salamanca: Sígueme.

García, A. (1998). Métodos y técnicas cualitativas en geografía social. Barcelona: Oikos-Tau.

González, G. (2003). Geografía Humanística. En: J. M. Nieto, (coord.) Logos Hellenikós: homenaje al Profesor Gaspar Morocho. Ponferrada: Universidad de León.

Gurevich, R. (2005). Sociedades y territorios en tiempos contemporáneos. México: Fondo de Cultura Económica.

Lindón, A. \& Hiernaux, D. (2006). Tratado de geografía humana. México: Anthropos.

Llorente, M. (2012). Literatura y espacio habitado. Diagonal, 31. Disponible en: http://www.revistadiagonal.com/diagonal-31/.

Massey, D. (2005). La filosofía y la política de la espacialidad: algunas consideraciones. En: Pensar este tiempo. Argentina: Paidós.

Morse, D. (2006). Asuntos críticos en los métodos de investigación cualitativa. Colombia: Facultad de Enfermería Universidad de Antioquia.
Ricoeur, P. (1999). Teoría de la interpretación. Discurso y excedente de sentido. México: Siglo xxı Editores.

Rivas, M. (1946). Los trabajadores de tierra caliente. Bogotá: Prensas de la Universidad Nacional de Colombia.

Santos, M. (2000). La naturaleza del espacio. España: Ariel.

Slawinski, J. (1989). El espacio en la literatura: distinciones elementales y evidencias introductorias. (Desiderio Navarro, trad.). T. 2. (pp. 265-287). La Habana: Textos y contextos.

Soja, E. (1997, segundo semestre). El tercer espacio. Ampliando el horizonte de la imaginación geográfica. Geographikos, 8, 2.

Thompson, J. (1993). Ideología y cultura moderna. Teoría crítica social en la era de la comunicación de masas. México: UAM-X.

Vasilachis, I. (2006). Estrategias de investigación cualitativa. Barcelona: Gedisa.

Vásquez, F. (2008). La enseña literaria. Crítica y didáctica de la literatura. Bogotá: Kimpres.

Verón, E. (1987). La semiosis social. Buenos Aires: Gedisa.

Villa, W. (2008/2010). Identidad, narrativas y conocimiento situado en la comprensión local para la reafirmación cultural. Humanismo y Ciencia. Revista Universidad Popular del Cesar, 1. 